Revista de

Contabilidade e

Organizações
DOI: http://dx.doi.org/10.11606/rco.v7i19.55509
Journal of

Accounting and

Organizations

\title{
A relação entre governança corporativa e gerenciamento de resultados em empresas brasileiras.
}

\author{
Claudio M. Ea. Barros; Rodrigo O. Soares ${ }^{\mathrm{b}}$; Gerlando A. S. Franco de Lima ${ }^{\mathrm{c}}$ \\ ${ }^{a}$ Departamento de Administração - Centro Universitário Unicuriti \\ ${ }^{b}$ Departamento de Administração - Universidade Federal do Parana \\ ${ }^{c}$ Faculdade de Economia, Administração e Contabilidade e Atuária - Universidade de São Paulo
}

\section{Informações do Artigo}

Histórico do Artigo

Recebido: 10 Maio de 2013

Aceito: 01 Novembro de 2013

Palavras chave

Gerenciamento de Resultados

Governança Corporativa

Discricionariedade

\begin{abstract}
Resumo
Este estudo teve como objetivo investigar a associação entre Governança Corporativa e gerenciamento de resultados contábeis em empresas brasileiras de capital aberto. A amostra do estudo é composta por 108 empresas listadas na BM\&FBOVESPA nos anos de 2008, 2009 e 2010. Como aproximação para a Governança Corporativa, utilizou-se o índice amplo proposto por Leal e Carvalhal da Silva (2005). Como proxy de gerenciamento de resultados, utilizaram-se os accruals discricionários estimados a partir do modelo proposto por Kang e Sivaramakrishnan (1995). Como variáveis de controle para associação ao Índice de Governança Corporativa, utilizaram-se as variáveis: tamanho, alavancagem financeira e desempenho. Considerando que a discricionariedade da gestão como resultado da separação entre propriedade e controle, e o conjunto de motivações associadas ao oportunismo, a hipótese subjacente do trabalho foi de que mecanismos Governança Corporativa comportem-se como inibidores do gerenciamento de resultados contábeis. Ao nível de significância de 1\%, observouse que a intensidade de gerenciamento de resultados é menor em empresas que apresentam presença mais marcante de atributos de Governança. Tais resultados corroboram as discussões sobre a presença de um trade-off entre estruturas de Governança Corporativa e escolhas contábeis direcionadas a gerenciar resultados contábeis.
\end{abstract}

Copyright (C) 2013 FEA-RP/USP. Todos os direitos reservados

\section{INTRODUÇÃO}

Diversos estudos no Brasil e no resto do mundo, que examinam a Governança Corporativa, buscam associar mecanismos de governança e desempenho econômico-financeiro de companhias. Em sua maioria, o intento desses trabalhos é descrever como atributos de governança exercem influência sobre a performance da firma. Tal verificação pode ser moldada de forma específica, como por exemplo, mediante a análise de características do Conselho de Administração, Comitês de Auditoria e práticas de Transparência, ou de maneira abrangente por meio do uso de índices amplos de Governança Corporativa (LEAL, 2004). Precedem às

Autor Correspondente: Tel +55 $413213-8700$

E-mail : (claudiomedwards@hotmail.com ) C. M. E. Barros; (rodrigoliveirasoares@gmail.com ) R. O. Soares; (gerlando@usp.br) G. A. S. F. de Lima.

Centro Universitário Unicuritiba, departamento de administração. Rua Chile 1678 - Rebouças, 80220 - 181 - Curitiba, PR - Brasil pesquisas empíricas, estudos que buscam estabelecer uma estrutura conceitual para embasar discussões que relacionem governança, finanças corporativas e mercado de capitais (SHLEIFER e VISHNY, 1997; LA PORTA et al., 1999; LA PORTA et al., 2000). Por sua vez, essas estruturas possibilitam reflexões que associam Governança Corporativa a temas de interesse profissional e acadêmico que não se restringem ao desempenho empresarial em termos de resultado ou valuation. Dentre essas temáticas adicionais, encontra-se a relação entre a Governança Corporativa e a intervenção proposital de gestores sobre os números contábeis, descrita como manipulação ou gerenciamento de resultados contábeis.

A perspectiva de investigações sobre Governança Corporativa está relacionada a problemas de agência, mais especificamente às implicações decorrentes da separação da propriedade e controle (SHLEIFER e VISHNY, 1997). Em essência, problemas de agência ocorrem porque interesses de agentes cooperativos (tais como, acionistas controladores, acionistas minoritários e diretores de empresas) podem não estar alinhados. Em face dessa divergência de interesses, característica marcante da separação da propriedade e controle, Jensen e Meckling (1976) e Watts e Zimmerman (1986) 
argumentam que a contabilidade pode exercer papel central nas relações de agência da moderna empresa, em função de sua capacidade de mitigar custos de agência. Esse papel de destaque é realçado por Bushman (2001, p.01) ao descrever que "a informação contábil é o produto da contabilidade corporativa e de sistemas de reporte externo que medem e divulgam informações ao público sobre dados quantitativos, sobre a posição financeira e desempenho de sociedades de capital aberto". Em direção semelhante, Lopes (2004) defende a contribuição da informação contábil como mecanismo de Governança Corporativa cujo intuito está em reduzir os impactos do conflito de agência. Fields, Lys e Vicent (2001) defendem que demonstrações financeiras são elaboradas por administradores que apresentam maior conhecimento sobre o desempenho da empresa e, portanto, tais agentes podem fazer escolhas contábeis que favoreçam interesses próprios em detrimento do interesse de investidores ou de outras partes relacionadas.

Administradores de uma companhia, seja de capital fechado ou com ações listadas em bolsa de valores, tem como responsabilidade primária assegurar que os sistemas de reporte financeiro garantam a mais alta qualidade de conteúdo prestado ao público (COHEN e KRISHNAMOORTHY, 2004). Entretanto, administradores fazem escolhas, as quais podem exercer influência sobre variáveis de desempenho econômicofinanceiro, tais como o lucro, a alavancagem operacional e financeira, dentre outras. Como partes interessadas no desempenho da empresa possuem a oportunidade de utilizar informações financeiras de domínio público, estas podem pautar decisões sobre seus investimentos a partir desses resultados que contêm vieses motivados por interesses específicos da gestão. Deparando-se com esse problema, o investidor teria sua percepção alterada e suas decisões seriam diferentes daquelas tomadas, caso o exercício da discricionariedade sobre os números contábeis não estivesse presente. Assim, a considerar a diversidade de estruturas de governança possíveis em companhias brasileiras, constitui-se como motivação deste trabalho o exame da presença da discricionariedade contábil em estruturas de Governança Corporativa.

A relação entre mecanismos de Governança Corporativa e indícios de gerenciamento de resultados tem atraído a atenção para o desenvolvimento de pesquisas empíricas e teóricas internacionais e nacionais (LARCKER et al., 2007; SHEN e CHIH, 2007; JIANG, LEE e ANANDARAJAN, 2008; BOWEN, RAJGOPAL e VENKATACHALAN, 2008; BEKIRIS e DOUKAKIS, 2011; CARDOSO, 2004, CARDOSO et al., 2006; RAMOS e MARTINEZ, 2006; BAPTISTA, 2009; TORRES et al., 2009). Ainda que por meio de métodos diferentes, essas pesquisas buscam estabelecer estruturas explicativas para a prática de Gerenciamento de Resultados a partir de atributos de Governança Corporativa. Tais estudos buscam demonstrar que a adoção de mecanismos de governança diminui a propensão de a empresa se envolver em gerenciamento de resultados. Em consequência, tende a exercer efeito positivo sobre a qualidade da informação contábil fornecida ao público de usuários.

Em estudos internacionais recentes que examinam a relação Gerenciamento de Resultados de Governança Corporativa, tem-se buscado notar não o efeito individualizado de variáveis de Governança, mas sim o seu efeito por meio da utilização de índices amplos (SHEN e CHIH, 2007; JIANG et at.,2008; BEKIRIS e DOUKAKIS, 2011). Essa abordagem não é frequente em pesquisas nacionais, as quais utilizam a classificação de empresas listadas em níveis diferenciados de Governança Corporativa na BM\&FBOVESPA. Diante desse contexto, a questão norteadora desta pesquisa é: Empresas brasileiras listadas na BM\&FBOVESPA que apresentam maior escore de governança corporativa apresentam menores níveis de gerenciamento de resultados contábeis?

Desse modo, esta pesquisa tem como objetivo investigar a associação entre atributos de Governança Corporativa e o Gerenciamento de Resultados contábeis. A considerar a discricionariedade da gestão como resultado da separação entre propriedade e controle, e o conjunto de motivações associadas ao oportunismo, a hipótese subjacente deste trabalho é de que mecanismos de Governança Corporativa comportem-se como inibidores do gerenciamento de resultados contábeis. Portanto, melhores estruturas de governança resultariam em menores níveis de gerenciamento de resultados contábeis.

Diferente de pesquisas nacionais com objetivos semelhantes, utilizou-se como método de mensuração dos accruals discricionários, variável equivalente ao gerenciamento de resultados, o Modelo Kang e Sivaramakrishnan (1995). Este estudo busca contribuir para a ampliação das investigações que explicam a relação entre variáveis contábeis e a Governança Corporativa em empresas brasileiras listadas em bolsa. Além disso, visa estimular a temática de pesquisa que analisa o desempenho de accruals discricionários a partir de índices amplos de Governança buscando evidências sobre a existência de um trade-off entre práticas de governança e gerenciamento de resultados.

\section{PLATAFORMA TEÓRICA}

\subsection{Governança corporativa}

Shleifer e Vishny (1997) argumentam que Governança Corporativa relaciona-se com as formas pelas quais investidores podem ter a certeza de que terão o retorno por investimentos realizados. Para Gillan e Starks (1998), pode ser definida como o sistema de leis, regras e fatores que conduzem as operações em uma companhia. Zingales (1998, p.3) estende o conceito definindo de sistemas de governança como o "complexo de restrições que moldam a barganha ex post sobre as quase-rendas geradas no curso da relação". Diante desses conceitos, pode-se entender Governança Corporativa como atributos de gestão que definem como a autoridade e a responsabilidade são distribuídas com o objetivo de se alinhar a interesses de investidores de recursos e gestores.

Leal (2004) buscou identificar as publicações mais influentes que examinassem o efeito de práticas de Governança Corporativa sobre o valor corporativo visualizado por meio do desempenho econômicofinanceiro e valor de mercado. A survey desenvolvida pelo autor levou em conta a literatura recente nacional e internacional e deu foco nas abordagens de: (1) concentração de direitos de fluxo de caixa e concentração de direitos de controle, e (2) utilização de índices amplos de Governança Corporativa. Algumas das evidências da primeira linha de estudos referem-se a artigos que 
reuniram evidências sobre a concentração de direitos de controle em empresas brasileiras (VALADARES e LEAL, 2000; LEAL e CARVALHAL- DA-SILVA, 2002); que documentaram a existência de custos e benefícios associados à concentração de propriedade e de estudos que sugerem que maiores direitos de fluxo de caixa estão associados a maiores valores de mercado das empresas (SHLEIFER e VISHNY, 1997; LA PORTA et al., 1998 e 2002; e CLAESSENS et al., 2002). Na linha seguinte de estudos identificada por Leal (2004), estão presentes estudos que utilizam um caminho alternativo para representar boas práticas de Governança Corporativa, mediante o uso de informações presentes em estatutos sociais e relatórios de informações públicas de empresas. Estes são denominados índices de Governança Corporativa.

Segundo Leal (2004), esses índices constituem-se no agrupamento de práticas de governança descritas na forma de atributos e buscam avaliar a qualidade das práticas de Governança Corporativa na forma de um escore ou coeficiente. Tais índices podem incluir práticas do conselho de administração, estrutura de propriedade, práticas de transparência, direitos de acionistas, presença de comitês específicos, dentre outras estruturas. Além disso, o objetivo desses índices é mensurar a qualidade de Governança Corporativa e analisar sua capacidade de influenciar ou de ser influenciada pelo desempenho das organizações.

Estudos sobre Governança Corporativa tornaramse frequentes na década de 90 e depois de escândalos empresariais que envolveram a expropriação de acionistas minoritários e falências de corporações consideradas bem geridas. Embora se argumente sobre a não existência de uma teoria para a Governança Corporativa (SILVEIRA, 2004), os desdobramentos das relações de agência e da separação da propriedade formalizados por Jensen e Meckeling (1976), Fama (1980), Fama e Jensen (1983) e Jensen (1983) oferecem uma vasta fonte teórica para o embasamento de estudos com essa temática.

$\mathrm{Na}$ literatura sobre finanças, defende-se que a presença da contabilidade e sua regulação seriam irrelevantes como conteúdo informacional. Fields, Lys e Vincent (2001) afirmam que "com mercados completos e perfeitos, não há papel substantivo para disclosures financeiros e, portanto, ausência de demanda pela contabilidade e sua regulação". Entretanto, segundo os mesmos autores, dada à presença de mercados imperfeitos e incompletos, a contabilidade se destaca como uma das maneiras para corrigir essas imperfeições e, portanto, capaz de produzir utilidade. A partir dessa interpretação, Fields, Lys e Vicent (2001) fundamentam a importância da contabilidade e buscam explicações para as escolhas contábeis de gestores a partir de três imperfeições de mercado: os custos de agência, assimetria de informação e externalidades intervenientes em partes não contratantes. Escolhas contábeis são dirigidas por essas imperfeições, as quais constituem motivação para parcela significativa de estudos sobre a associação de Governança Corporativa ao desempenho organizacional. Assim, espera-se que esse conjunto de elementos teóricos contribua para explicação da relação entre governança e discricionariedade dos gestores sobre os números contábeis.

Sloan (2001) investigou a evolução temática de estudos que associam governança corporativa e a contabilidade em que observou três categorias: i) estudos sobre a relação entre custo de capital e disclosure; ii) pesquisas sobre a efetividade de mecanismos de monitoramento e reporte de informações financeiras; e iii) investigação de efeitos e consequências de falhas no processo de reporte de informações financeiras. Nessa última categoria, encontram-se estudos sobre o gerenciamento de resultados contábeis. Mediante o fato de que se mostra clara a ligação entre contabilidade e Governança Corporativa (SLOAN, 2001; BUSHMAN e SMITH, 2001), este trabalho busca realçar a contribuição da contabilidade ao investigar a relação entre proxies de gerenciamento e a Governança Corporativa não de maneira isolada, mas de forma ampla por meios de indicadores.

\subsection{Gerenciamento de resultados}

Estudos internacionais e nacionais buscaram evidências da prática de gerenciamento de resultados em companhias abertas a partir da observação de determinadas regularidades evidenciadas a partir das demonstrações contábeis (DECHOW, SLOAN e SWEENY, 1995; MCNICHOLS, 2000; MARTINEZ, 2001; COELHO e LOPES, 2007; NARDI e NAKAO, 2009). O que esses estudos possuem em comum é apresentar indícios de gerenciamento de resultados, buscando descrever os reflexos danosos dessa prática sobre o mercado de capitais. No campo teórico, o trabalho de Schipper (1989) destaca-se pela busca em desenvolver uma estrutura conceitual para o tema a partir de pesquisas que: (1) associassem escolhas contábeis e gerenciamento de resultados e (2) buscassem delinear uma conexão entre pesquisa sobre gerenciamento de resultados e outras áreas da contabilidade. A partir desse estudo, o autor definiu o objeto de pesquisa sobre gerenciamento de resultados e estabeleceu um traço marcante para determinação dos fatores que motivam a sua prática quando afirma que:

(...) a perspectiva informacional do gerenciamento de resultados assume que gestores têm informações privilegiadas que podem ser usadas quando eles escolhem elementos de um conjunto normativo de regras para reporte de informações sob um determinado conjunto de contratos que determinam, por exemplo, remuneração.

Sob a perspectiva do processo de elaboração da informação contábil, coloca-se em questão a existência de incentivos para que gestores interfiram para não demonstrar o desempenho subjacente da organização, ainda que dentro da amplitude permitida pelos princípios contábeis. Nessa direção, Healy e Wahlen (1999, p.06) apresentam a seguinte definição para gerenciamento de resultados contábeis:

Gerenciamento de resultados ocorre quando gestores usam o julgamento em relatórios financeiros e estrutura de transações para alterar o reporte de informações com o objetivo de induzir ao erro as partes interessadas no negócio sobre o desempenho subjacente da companhia ou para influenciar resultados contratuais que dependem de números produzidos pela contabilidade.

Healy e Wahlen (1999) sumarizam o surgimento da prática do Gerenciamento de Resultados a partir de três conjuntos de motivações: i) Motivações envolvendo o mercado de capitais: o uso generalizado da informação contábil por investidores e analistas financeiros, associado à valoração do preço de ações podem criar incentivos aos gestores para manipular 
lucros em uma tentação em influenciar a performance dos preços dos ativos no curto prazo; ii) Motivações contratuais: Informações contábeis são utilizadas para monitorar e regular dispositivos contratuais entre a empresa e partes interessadas (tais como fornecedores de recursos) que utilizam a informação contábil para construir uma opinião sobre as condições da companhia e tomar decisões. Externa ou internamente, contratos de compensação (remuneração) são usados para alinhar os incentivos do gestor e acionistas. Esses contratos podem criar incentivos para prática de Gerenciamento de Resultados; iii) Motivações regulatórias: incentivos associados ao "manejo" do lucro de companhias que atuam em mercados monitorados por agências de regulação. Empresas que têm sua atividade regulada pelo governo podem manipular resultados para atender objetivos específicos.

Dada à extensão do que pode dar causa à prática de gerenciamento de resultados, Fields, Lys e Vicent (2001) defendem que o conceito de escolhas contábeis é mais restrito, pois nem todas as escolhas contábeis ensejam em gerenciamento de resultados contábeis. Segundo os autores (2001, p.6), "Embora nem todas as escolhas contábeis envolvam gerenciamento de resultados, este termo vai além da definição escolhas contábeis, as implicações das escolhas contábeis para alcançar um objetivo são consistentes a ideia de gerenciamento de resultados". Entretanto, indícios de gerenciamento de resultados podem ser efeitos de escolhas contábeis feitas por gestores, as quais podem ser influenciadas por um conjunto de motivações ou por mecanismos de controle e gestão.

\subsection{Pesquisas sobre governança corporativa $e$} gerenciamento de resultados

Nesta seção, são apresentados os resultados de pesquisas internacionais que examinaram a associação entre Governança Corporativa e Gerenciamento de resultados, utilizando índices amplos de governança como fator explicativo para o nível de gerenciamento de resultados contábeis.

\begin{tabular}{|c|c|c|c|c|}
\hline Autores & Ano & País de origem & Tipo de Análise & Relação encontrada \\
\hline Larcker et al. & 2007 & Estados Unidos & Multivariada & Negativa e significativa \\
\hline Shen e Chih & 2007 & China & Multivariada & Negativa e significativa \\
\hline Chen, Elder e Hsieh & 2007 & Taiwan e EUA & Multivariada & Negativa e Significativa \\
\hline Bowen, Rajgopal e Venkatachalam & 2008 & Estados Unidos & Multivariada & Negativa e significativa \\
\hline Jiang, Lee e Anandarajan & 2008 & Estados Unidos & Multivariada & Negativa e significativa \\
\hline Shah, Butt e Hasan & 2008 & Paquistão & Univariada & Positiva e Significativa \\
\hline Bekiris e Doukakis & 2011 & Grécia e Suíça & Multivariada & Negativa e Significativa \\
\hline
\end{tabular}

Quadro 1. Estudos anteriores sobre Gerenciamento de Resultados e Governança Corporativa

Fonte: os autores

A maioria das pesquisas internacionais que exploraram a relação Gerenciamento de Resultados e Governança Corporativa evidenciou que atributos de governança podem exercer efeito benéfico na direção de mitigação da prática discricionária de gestores sobre as informações contábeis, a exceção para a experiência paquistanesa. Desse modo, há evidências de que a qualidade de governança pode ser um fator explicativo para diminuir a propensão da empresa em gerenciar resultados e aumentar a qualidade da informação contábil disponibilizada ao usuário da informação.

Em pesquisas nacionais, comumente utiliza-se como proxy de governança corporativa os Níveis Diferenciados de Governança Corporativa (NDGC) e não índices amplos. Cardoso et al. (2006) investigaram a relação entre accruals discricionários, liquidez e Governança Corporativa. O objetivo da pesquisa foi verificar se práticas de Governança Corporativa poderiam inibir práticas de Gerenciamento de Resultados. O período de análise foi 1997 a 2004 com o total de 1.791 observações. O modelo econométrico utilizado para mensuração das accruals discricionários foi o modelo Jones (1991). O trabalho constatou que não há diferença estatisticamente significativa da intensidade de accruals discricionários entre empresas listadas em níveis diferençados de Governança Corporativa e aquelas que não são.

Por meio de premissas semelhantes ao da pesquisa anterior, Ramos e Martinez (2006) discutiram a relação entre a prática de Gerenciamento de Resultados e Conselho de Administração, conselho fiscal e auditoria. Embora o estudo tenha verificado que empresas sem classificação de Governança Corporativa convivem com maior variabilidade de accruals discricionários, não foi possível concluir sobre menores níveis de accruals discricionários associados a níveis mais elevados de governança corporativa.

Lopes e Walker (2008) realizaram um experimento comparativo de empresas brasileiras e norte-americanas com o objetivo de examinar a influência de determinados tipos de incentivos sobre a qualidade das demonstrações financeiras de empresas brasileiras. As constatações do trabalho, que foi o primeiro a incorporar o uso de índices de governança como proxy de governança corporativa na análise da qualidade de relatórios contábeis, são de que (1) empresas brasileiras com oportunidades de crescimento adotam medidas voluntárias de aprimoramento dos seus modelos de governança corporativa e a (2) implementação de mecanismos mais rígidos de governança podem exercem influência negativa sobre o gerenciamento de resultados contábeis.

Por meio dessa revisão de pesquisas, visualiza-se que em estudos nacionais não se utilizam, com frequência, índices amplos de Governança em associação ao Gerenciamento de Resultados. Desse modo, pode-se indicar a possibilidade de evolução dessa linha temática de estudos no Brasil com objetivo subjacente de verificar se mecanismos de governança exercem influência relevante sobre escolhas contábeis de gestores e, consequentemente, sobre a qualidade dos números contábeis. 


\section{PROCEDIMENTOS METODOLÓGICOS}

A população desta pesquisa consiste nas empresas brasileiras de capital aberto com ações negociadas na BM\&FBOVESPA. A amostra é composta por empresas não financeiras que dispunham das informações contábeis e de mercado para mensuração das variáveis de pesquisa de 2008 a 2010. A amostra da pesquisa corresponde a 111 empresas dividas em 17 setores econômicos totalizando 308 observações.

Em relação à coleta de dados, há informações de natureza primária e secundária. Os dados primários referem-se às informações necessárias para construção do índice amplo de governança corporativa (IGC), cuja fonte foi o website da Comissão de Valores Mobiliários (CVM). Já a coleta de dados secundários, deu-se a partir da base de dados Economática ${ }^{\circledR}$, cujo objetivo foi obter as variáveis contábeis do modelo de estimação de accruals discricionários e demais variáveis da pesquisa.

\section{1 Índice de Governança Corporativa}

Para mensuração do nível de GC das empresas da amostra, foi utilizado o índice amplo proposto por Leal e Carvalhal-da-Silva (2005) conforme Quadro 2.

\begin{tabular}{|c|c|}
\hline & TRANSPARÊNCIA \\
\hline 1 & $\begin{array}{l}\text { A companhia prepara seus relatórios financeiros exigidos } \\
\text { por lei dentro do prazo previsto? }\end{array}$ \\
\hline 2 & $\begin{array}{l}\text { A companhia utiliza métodos internacionais de } \\
\text { contabilidade? }\end{array}$ \\
\hline \multirow[t]{2}{*}{3} & $\begin{array}{l}\text { A companhia usa uma das principais empresas de } \\
\text { auditoria globais? }\end{array}$ \\
\hline & COMPOSIÇÃO E FUNCIONAMENTO DO CONSELHO \\
\hline 4 & $\begin{array}{l}\text { O presidente do conselho e o diretor geral da empresa são } \\
\text { pessoas diferentes? }\end{array}$ \\
\hline 5 & $\begin{array}{l}\text { O conselho é claramente composto por conselheiros } \\
\text { externos e possivelmente independentes (não ligados aos } \\
\text { controladores)? }\end{array}$ \\
\hline 6 & $\begin{array}{l}\text { O conselho possui entre } 5 \text { e } 9 \text { membros, conforme } \\
\text { recomenda o IBGC? }\end{array}$ \\
\hline 7 & $\begin{array}{l}\text { Os membros do conselho possuem mandato de um ano, } \\
\text { conforme recomenda o IBGC? }\end{array}$ \\
\hline \multirow[t]{2}{*}{8} & Há na companhia conselho fiscal permanente? \\
\hline & CONTROLE E CONDUTA \\
\hline 9 & $\begin{array}{l}\text { O grupo controlador, considerando o acordo de acionistas, } \\
\text { possui menos de } 50 \% \text { das ações com direito a voto? }\end{array}$ \\
\hline 10 & $\begin{array}{l}\text { A porcentagem de ações sem direito a voto é menor que } \\
20 \% \text { do total do capital? }\end{array}$ \\
\hline 11 & $\begin{array}{l}\text { O índice de acionistas controladores de direitos de fluxos } \\
\text { de caixa para direitos de voto é maior ou igual a } 1 ?\end{array}$ \\
\hline \multirow[t]{2}{*}{12} & $\begin{array}{l}\text { O free-float da companhia é maior ou igual ao que é } \\
\text { requerido pela bolsa de valores de São Paulo para o "Novo } \\
\text { Mercado" }(25 \%) \text { ? }\end{array}$ \\
\hline & DIREITOS DE ACIONISTAS \\
\hline 13 & $\begin{array}{l}\text { O contrato social da companhia estabelece câmara de } \\
\text { arbitragem para resolver conflitos corporativos? }\end{array}$ \\
\hline 14 & $\begin{array}{l}\text { O contrato social da companhia concede direitos adicionais } \\
\text { de voto além do que é legalmente requerido? }\end{array}$ \\
\hline 15 & $\begin{array}{l}\text { A companhia concede direitos de concede tag along além } \\
\text { do que é legalmente requerido? }\end{array}$ \\
\hline
\end{tabular}

Quadro 2. Índice de Governança Corporativa

Fonte: Leal e Carvalhal-da-Silva (2005).
Desse modo, o nível das práticas de governança corporativa será avaliado a partir de constructos compostos por variáveis dicotômicas (e sem ponderação) que se referem à presença ou ausência de atributos específicos de governança corporativa. Caso esteja presente na estrutura de governança da empresa o atributo, a questão recebe nota 1 (um), caso contrário, 0 (zero). O ICG poderá ser demonstrado na forma de Rating variando de 0 a 15 ou convertido em percentual variando de $0 \%$ a $100 \%$. Portanto, quanto maior o rating ou percentual do IGC apresentado pela firma da amostra, mais elevada será sua estrutura de Governança Corporativa. Na mesma direção da investigação de Leal e Carvalhal-da-Silva (2005), os escores de governança calculados serão divididos em três grupos: i) Alta Governança: empresas com rating de 10 a 15; ii) Média Governança: empresas com rating de 5 a 9; e iii) Baixa Governança: empresas com rating até 4.

\subsection{Estimação dos accruals discricionários}

O método utilizado na mensuração dos accruals discricionários para identificação de gerenciamento de resultados foi o modelo proposto por Kang-Sivaramakrishnan (1995), em que a variável representativa dos accruals discricionários (AD) é o valor resultante do erro da regressão múltipla computada a partir das variáveis do modelo. $\mathrm{O}$ modelo assume que os accruals totais (AT) representam a diferença absoluta entre o fluxo de caixa e os ajustes decorrentes do princípio da competência. Considera-se que accruals totais a soma dos accruals não discricionários (AND) e discricionários. Os AND são os ajustes e medidas intrínsecos da atividade e os discricionários seriam ajustes propositais da gestão com o objetivo de aumentar ou diminuir o resultado da uempresa. Diante disso, há a seguinte igualdade:

$$
\text { ATit }=\text { ANDit }+ \text { ADit (1) }
$$

Em que:

$A T_{i t}$ : São os accruals totais da empresa i no ano t; $A N D_{i t}$ : São os accruals não discricionários da empresa i no ano t;

$A D_{i t}$ : São os accruals discricionários da empresa i no t;

O modelo KS (1995) considera no vetor de variáveis explicativas dos accruals totais as variáveis de receita, despesas e equipamentos e plantéis de propriedade da empresa. Tem a seguinte configuração:

$$
\begin{gathered}
\mathrm{A} T_{i t}=\phi_{0}+\phi_{1}\left[\delta_{l} \operatorname{Rec}_{i t}\right]+\phi_{2}\left[\delta_{2} \operatorname{Desp}_{i t}\right]+\phi_{-} 3\left[\delta_{3} A t . I m o b_{i t}\right. \\
]+\beta P A R T_{i t}+\varepsilon_{i t}(2)
\end{gathered}
$$

Em que:

$R e c_{\text {it }}$ são as receitas líquidas da empresa $i$ escaladas pelo ativo total no ano $t$; 
Desp são as despesas da empresa $i$ escaladas pelo ativo total no ano $t$

At.Imob ${ }_{i t}$ representam o total das plantas, equipamentos e propriedade da empresa $i$ no ano $t$;

$\phi_{1}, \phi_{2}$ e $\phi_{3}$ são os coeficientes da equação de regressão que serão utilizados para estimar os accruals discricionários;

$\beta$ PART $_{\text {it }}$ é o coeficiente de regressão que busca captar um efeito significativo da amostra de pesquisa.

$\varepsilon_{\mathrm{it}}$ é o componente de erro mensurado indiretamente que indica a proxy de gerenciamento de resultados.

Os $\delta_{1}, \delta_{2}$ e $\delta_{3}$ parâmetros são indicadores associados a cada uma dessas variáveis levando em conta a hipótese que as variáveis do modelo não sejam manipuladas. São representadas pelas seguintes igualdades:

$$
\begin{gathered}
\delta_{1}=\left(\operatorname{AR}_{(t-1)}^{*}\right) /\left(\operatorname{REV}^{*}{ }_{(t-1)}\right)(3), \delta_{2}=\left(\operatorname{ABP}^{*}{ }_{(t-1)}^{*}\right) /\left(\operatorname{EXP}_{(t-1)}^{*}\right) \\
\delta_{3}=(4),
\end{gathered}
$$

O passo seguinte foi estimar os coeficientes da regressão para as variáveis de receita despesa e imobilizado. A equação 3 contém a violação de um pressuposto do método dos Mínimos Quadrados
Ordinários (MQO). Esta ocorre quando as variáveis independentes são contemporaneamente correlacionadas com o termo de erro $\varepsilon$ (ADKINS, 2011). É representada por $\operatorname{Cov}\left(X_{i} \varepsilon_{i}\right)=E\left(X_{i} \varepsilon_{i}\right) \neq 0$. O efeito desse problema é a estimação de coeficientes de regressão enviesados e inconsistentes, o que para a aplicação do Modelo KS (1995) é inadequado, uma vez que o componente do modelo que representa o gerenciamento de resultados está na estimação dos erros $(\varepsilon)$. A alternativa estatística para solução desse problema é utilizar Variáveis Instrumentais (VI) para estimação dos coeficientes da regressão.

Uma VI, $z$, é uma variável correlacionada com $x$, mas não correlacionada com o termo de erro $\varepsilon$ (GUJARATI, 2004). Ao contrário da utilização do modelo MQO, na utilização de variáveis instrumentais e aplicação de Mínimos Quadrados de dois Estágios (M2QO), pode-se estimar regressores consistentes.

O princípio para o emprego de variáveis instrumentais está em identificar proxies para o vetor de variáveis explicativas (GREENE, 2003). Nesse sentido, proxies são variáveis que, embora estejam correlacionadas com as variáveis independentes, não estão correlacionadas com o termo de erro $\varepsilon$. Encontrar essas proxies indica a remoção da violação do pressuposto discutido acima. Para localizar as VI para as variáveis de Receitas, Despesas e Ativo Imobilizado, foram realizadas defasagens como

\begin{tabular}{|c|c|c|}
\hline Variável & Forma apresentada na equação 2 & Instrumento da variável \\
\hline Receita & $\begin{array}{c}\left(\phi_{1}\left[\delta_{1} \operatorname{Rec}_{\mathrm{it}}\right]\right) / \text { Ativo }_{\mathrm{t}} \\
\delta_{1}=\text { Contas a receber }_{(\mathrm{t}-1)} / \operatorname{Receita}_{(\mathrm{t}-1)}\end{array}$ & $\begin{array}{l}\quad\left(\phi_{1}\left[\delta_{1} \operatorname{Rec}_{\mathrm{it}}\right]\right) / \operatorname{Ativo}_{(\mathrm{t}-1)} \\
\text { Em que: } \\
\delta_{1}=\text { Contas a receber }_{(\mathrm{t}-2)} / \text { Receita }_{(t-2)}\end{array}$ \\
\hline Despesas & $\begin{array}{l}\qquad\left(\phi_{2}\left[\delta_{2} \operatorname{Desp}_{\mathrm{it}}\right]\right) / \text { Ativo }_{\mathrm{t}} \\
\text { Em que: } \\
\delta_{2}=\text { Cap.de giro líquido } \\
(\mathrm{t}-1) \\
- \text { Contas a rece. }_{(\mathrm{t}-1)} / \text { Receita }_{(\mathrm{t}-1)}\end{array}$ & $\begin{array}{l}\qquad\left(\phi_{2}\left[\delta_{2} \operatorname{Desp}_{\mathrm{it}}\right]\right) / \text { Ativo }_{(\mathrm{t}-1)} \\
\text { Em que: } \\
\delta_{2}=\text { Cap.de giro líquido } \\
(\mathrm{t}-2)\end{array}$ \\
\hline $\begin{array}{c}\text { Ativo } \\
\text { Imobilizado }\end{array}$ & 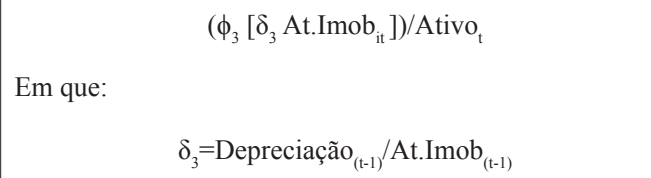 & $\begin{array}{l}\quad\left(\phi_{3}\left[\delta_{3} \text { At.Imob }_{\mathrm{it}}\right]\right) / \text { Ativo }_{\mathrm{t}} \\
\text { Em que: } \delta_{3}=\text { Depreciação }_{(\mathrm{t}-\mathrm{l})} / \mathrm{At}^{\mathrm{A}} \operatorname{Imob}_{(\mathrm{t}-1)}\end{array}$ \\
\hline
\end{tabular}
apresentado no Quadro 2.

Quadro 3. descrição das variáveis instrumentais utilizadas.

Fonte: o autor.

Embora o período de pesquisa tenha sido de três anos, foram necessárias informações contábeis de 2 anos anteriores a 2008. Essa coleta de dois anos precedentes ao período de análise decorre-se da necessidade de identificar instrumentos para o vetor de variáveis que representam os accruals não discricionários. Na coluna instrumento da variável do Quadro 1, Receita e Despesas do modelo KS (1995) foram defasadas em um período. No modelo demonstrado pela equação 4, essas variáveis estavam escaladas pelo ativo total no período $t$. Para identificar a proxy, as variáveis foram defasadas pelo ativo total no período $t$ - 1 . Para os indicadores $\delta 1$ e $\delta 2$, adotou-se o mesmo procedimento e ambos foram defasados em um período. Optou-se por não efetuar alterações na variável ativo imobilizado, pois essa variável foi considerada preditora e instrumental simultaneamente, o que é aceito pela prática de Mínimos Quadrados de dois Estágios (ADKINS, 2011).

$\mathrm{Na}$ sequência, foi verificada a robustez (fraqueza ou força) dos instrumentos por meio da aplicação do teste de Cragg-Donald e sua justificativa, conforme Tabela 1. A hipótese nula desse teste é de que os instrumentos verificados são fracos. 
Tabela 1. coeficientes da regressão do modelo KS (1995)

\begin{tabular}{|c|c|c|c|}
\hline Variável & Forma(equação 10) & Proxy da variável & Coeficientes \\
\hline Receita & $\left(\phi_{1}\left[\delta_{1} \operatorname{Rec}_{\mathrm{it}}\right]\right) /$ Ativo $_{\mathrm{t}}$ & $\left(\phi_{1}\left[\delta_{1} \operatorname{Rec}_{i t}\right]\right) /$ Ativo $_{(t-1)}$ & $0,216^{* * *}$ \\
\hline Despesas & $\left(\phi_{2}\left[\delta_{2}\right.\right.$ Desp $\left.\left._{\mathrm{it}}\right]\right) /$ Ativo $_{\mathrm{t}}$ & $\left(\phi_{2}\left[\delta_{2} \operatorname{Desp}_{\mathrm{it}}\right]\right) /$ Ativo $_{(\mathrm{t}-1)}$ & $-0,063 *$ \\
\hline $\begin{array}{c}\text { Ativo } \\
\text { Imobilizado }\end{array}$ & $\left(\phi_{3}\left[\delta_{3}\right.\right.$ At.Imob $\left.\left._{\mathrm{it}}\right]\right) /$ Ativo $_{\mathrm{t}}$ & $\left(\phi_{3}\left[\delta_{3}\right.\right.$ At.Imob $\left.\left._{\mathrm{it}}\right]\right) /$ Ativo $_{\mathrm{t}}$ & $-0,838 * * *$ \\
\hline Intercepto & $\phi_{0}$ & $\phi_{0}$ & $-0,258^{*}$ \\
\hline
\end{tabular}

Fonte: o autor. *significativo em $10 \%$. $* *$ significativo em $5 \%$. $* * *$ significativo em $1 \%$

A Tabela 1 demonstra que os coeficientes das variáveis do modelo apresentam-se significativos ao nível de $1 \%$ e $10 \%$ para explicar a variação dos accruals totais (AT), inclusive o intercepto. Entretanto, não é possível afirmar somente a partir do resultado da significância que esses instrumentos podem ser considerados proxies adequadas.

Stock e Yogo (2005) desenvolveram uma tabela de valores críticos para instrumentos fracos. Caso o valor do teste exceda o valor crítico, rejeita-se a hipótese de fraqueza dos instrumentos em questão. Considerando que o resultado do teste estatístico Cragg-Donald foi de 232,61 , pode-se concluir que os instrumentos representam proxies adequadas das variáveis preditoras. Diante disso, os coeficientes de regressão utilizados para estimação dos accruals discricionários (AD) são os descritos na Tabela 1. Desse modo, a partir dos coeficientes da tabela
1, podem-se estimar os erros da regressão os quais representam a proxy de gerenciamento de resultados em que maiores níveis de gerenciamento de resultados são estimados por maiores níveis de accruals discricionários (AD) calculados a partir das especificações do modelo KS (2005).

\subsection{Variáveis de controle}

No quadro 4, são apresentadas as variáveis de controle utilizadas com o objetivo de observar sua regularidade de comportamento em relação ao IGC. Mostram-se também referências de estudos precedentes que utilizaram as variáveis de controle incluídas neste estudo em relação à Governança Corporativa.

\begin{tabular}{|c|c|c|c|c|}
\hline Variável & Sigla & $\begin{array}{c}\text { Relação } \\
\text { esperada }\end{array}$ & $\begin{array}{l}\text { Forma de } \\
\text { cálculo }\end{array}$ & Referências \\
\hline Tamanho & $T A M_{i t}$ & + & $\begin{array}{c}\text { Logaritmo } \\
\text { natural do ativo } \\
\text { total no período } \\
t .\end{array}$ & $\begin{array}{l}\text { Empresas de maior porte apresentam maior necessidade de captação de } \\
\text { recursos externos para financiar seus investimentos e, também para manter } \\
\text { a estrutura necessária para implementação de mecanismos de Governança } \\
\text { Corporativa (SILVEIRA, 2004). Adicionalmente, argumenta-se que empresas } \\
\text { maiores são dotadas de maior complexidade e por isso precisam ser dirigidas } \\
\text { mediante atributos de maior nível (BLACK, JANG e KIM, 2006) }\end{array}$ \\
\hline Alavancagem & $A L A V_{i t}$ & + & $\begin{array}{l}\text { Razão do total } \\
\text { de dívidas de } \\
\text { longo prazo no } \\
\text { período } t \text { e o } \\
\text { ativo total em } \\
\quad t-1 \text {. }\end{array}$ & $\begin{array}{l}\text { A relação esperada para a alavancagem e o IGC é positiva porque atributos } \\
\text { que reduzem custos de agência exercem papel central para determinação do } \\
\text { grau de endividamento das empresas (BUTT, 2011). No Brasil evidências } \\
\text { dessa relação são convergentes a esta expectativa (LEAL e CARVALHAL- } \\
\text { DA-SILVA, 2005) }\end{array}$ \\
\hline $\begin{array}{l}\text { Retorno } \\
\text { sobre os } \\
\text { Ativos }\end{array}$ & $R O A_{i t}$ & + & $\begin{array}{l}\text { Razão do lucro } \\
\text { líquido do } \\
\text { período } t \text { e o } \\
\text { ativo total de } \\
t-1 .\end{array}$ & $\begin{array}{l}\text { Espera-se que empresas que desempenhem melhor rentabilidade apresentem } \\
\text { escore elevado de Governança Corporativa (KLAPPER e LOVE, 2004; } \\
\text { BROWN e CAYLOR, 2009). }\end{array}$ \\
\hline
\end{tabular}

Quadro 4. Variáveis de controle

Fonte: os autores

Com o objetivo de se verificar se as variáveis de pesquisas seguem distribuição normal foi aplicado o teste de Kolmorogov-Smirnov. A tabela 2 apresenta os resultados desse teste.

Tabela 2. Teste K-S de Normalidade

\begin{tabular}{cc}
\hline Variáveis & Escore $\mathbf{Z}$ \\
\hline$I G C_{i t}$ & $2,444 * * *$ \\
\hline$A D_{i t}$ & $2,925^{* * *}$ \\
\hline$T A M_{i t}$ & 1,205 \\
\hline$A L A V_{i t}$ & $3,439 * * *$ \\
\hline$R O A_{i t}$ & $2,771^{* * *}$ \\
\hline
\end{tabular}

Fonte: os autores. *significativo em $10 \%$.

**significativo em $5 \%$.***significativo em $1 \%$
Ao nível de $1 \%$, é possível afirmar que as variáveis Índice de Governança Corporativa, Accruals discricionários, Alavancagem e Retorno sobre os ativos não seguem uma distribuição que se aproxime de uma distribuição normal. Desse modo, a análise de dados levará em consideração a rejeição da hipótese de normalidade e utilizará testes não paramétricos.

A observação da normalidade da distribuição de dados de um determinado conjunto constitui uma das hipóteses para aplicação de testes paramétricos, tais como teste $t$, anova-one way, anova-two way e outros. Entretanto, há alternativas para inferências sobre possíveis diferenças entre médias (ou medianas) de duas ou mais amostras que apresentam distribuições que se distanciam de uma distribuição normal. Tratam-se dos testes não paramétricos também chamados de testes de 
distribuição livre (FIELD, 2009).

$\mathrm{Na}$ literatura existem testes não paramétricos equivalentes para situações que se deseja analisar e se tem distribuição normal de dados, como por exemplo, o teste Mann Whitney para amostras independentes e não emparelhadas. Esse teste é utilizado quando se deseja utilizar o teste $t$ de diferença de médias de duas amostras, mas não se tem normalidade dos dados. A aplicabilidade dos testes não paramétricos não é restrita à verificação de possíveis diferenças estatisticamente significativas entre médias.

Assim, a verificação de diferenças entre os níveis de accruals discricionários das empresas que compõe o subgrupo de companhias com alta e baixa estrutura de Governança Corporativa, levará em consideração a ausência de normalidade apresentada nas variáveis de pesquisa e utilizará o teste de Mann U Whitney de diferença de médias.

\subsection{Hipótese de pesquisa}

Formalizações teóricas sobre os efeitos da separação da propriedade e controle fundamentam estudos sobre Governança Corporativa. A expectativa do fornecedor de recursos é a de que quanto mais elevada for a estrutura de governança da entidade, menores serão os custos de agência em termos de alinhamento de interesses entre gestores e investidores. Dessa forma, espera-se que estruturas mais elevadas de governança imponham limitações a gestores em exercer a discricionariedade, o que resultaria em menor intensidade de gerenciamento de resultados. Essa argumentação fundamenta a seguinte hipótese de pesquisa:

$\mathrm{H}_{0}$ : Escores maiores do Índice de Governança Corporativa (IGC) não estão associados a menores níveis de gerenciamento de resultados.

\section{ANÁLISE DE RESULTADOS}

Nesta seção, busca-se explorar a regularidade e interpretar os resultados da amostra de pesquisa a partir do percurso metodológico estabelecido nas seções anteriores.

\subsection{Estatísticas descritivas}

Nesta etapa, apresentam-se os resultados da estatística descritiva das variáveis de pesquisa que incluem, também, a análise bivariada das variáveis. Na tabela 3 , faz-se uma análise exploratória dos dados.

Tabela 3. estatística descritiva das variáveis de pesquisa

\begin{tabular}{|c|c|c|c|c|c|}
\hline Variável & Mínimo & Média & Desvio Padrão & Máximo & $\begin{array}{l}\text { Coeficiente de } \\
\text { Variação }\end{array}$ \\
\hline$I G C_{i t}$ & $13,33 \%$ & $47,08 \%$ & $21,42 \%$ & $93,33 \%$ & 0,4549 \\
\hline$A D_{i t}$ & 0,0001 & 0,0578 & 0,0596 & 0,4217 & 1,0319 \\
\hline$T A M_{i t}$ & 8,9046 & 14,1155 & 1,7714 & 20,0693 & 0,1255 \\
\hline$A L A V_{i t}$ & 0,0000 & 0,1565 & 0,1828 & 1,9379 & 1,1681 \\
\hline$R O A_{i t}$ & $-1,0239$ & 0,0663 & 0,1501 & 0,8876 & 2,2637 \\
\hline
\end{tabular}

Fonte: os autores

Observa-se que a variável AD apresenta exclusivamente valores positivos. Pesquisas nacionais e internacionais que examinam escolhas contábeis observam que accruals discricionários positivos são utilizados para aumentar resultados e negativos para diminuí-los (MARTINEZ, 2006).

Como a hipótese deste trabalho é de que mecanismos de governança exercem influência negativa sobre a discricionariedade do gestor e que gestores podem ter incentivos para reduzir ou aumentar resultados para defender interesses individuais, as estimações dos accruals discricionários foram convertidas em valores absolutos, ou seja, em módulo. Metodologia semelhante para análise dos accruals discricionários foi utilizada por Cardoso et al. (2006). dispersão elevada se comparada com as outras variáveis de pesquisa. Isso é explicado pelo seu método de mensuração ser realizado a partir da ausência ou presença de atributos de governança para cada uma das empresas da amostra. Na tabela 3, o IGC está apresentado na forma de percentual em que a empresa com menor nível de Governança Corporativa tem $13,3 \%$ dos atributos do instrumento de pesquisa utilizado e a empresa com maior nível tem $93,33 \%$.

$\mathrm{Na}$ tabela 4, pode-se fazer uma análise dos escores de Governança a partir dos ratings obtidos por cada empresa da amostra por ano. Essa metodologia vai ao encontro de Leal e Carvalhal-da-Silva (2005), em que se classificam a amostra em empresas com "baixo", "médio" e "alto" escore de governança.

Ainda na tabela 3 , observa-se que a variável IGC tem 
Tabela 4. Escores do índice geral de Governança Corporativa

\begin{tabular}{|c|c|c|c|c|c|}
\hline $\begin{array}{c}\text { Nível de } \\
\text { Governança }\end{array}$ & IGC & 2008 & 2009 & 2010 & $\begin{array}{c}\text { AD } \\
\text { Médio }\end{array}$ \\
\hline \multirow{7}{*}{$\begin{array}{c}\text { Alta } \\
\text { Governança }\end{array}$} & 15 & 0 & 0 & 0 & \multirow{7}{*}{0,0464} \\
\hline & 14 & 2 & 2 & 2 & \\
\hline & 13 & 5 & 6 & 6 & \\
\hline & 12 & 4 & 7 & 7 & \\
\hline & 11 & 5 & 4 & 6 & \\
\hline & 10 & 7 & 7 & 3 & \\
\hline & Subtotal & 23 & 26 & 24 & \\
\hline \multirow{6}{*}{$\begin{array}{c}\text { Média } \\
\text { Governança }\end{array}$} & 9 & 2 & 8 & 7 & \multirow{6}{*}{0,0601} \\
\hline & 8 & 7 & 3 & 15 & \\
\hline & 7 & 5 & 18 & 12 & \\
\hline & 6 & 20 & 15 & 14 & \\
\hline & 5 & 17 & 13 & 10 & \\
\hline & Subtotal & 51 & 57 & 58 & \\
\hline \multirow{7}{*}{$\begin{array}{c}\text { Baixa } \\
\text { Governança }\end{array}$} & 4 & 11 & 12 & 9 & \multirow{7}{*}{0,0625} \\
\hline & 3 & 10 & 4 & 8 & \\
\hline & 2 & 8 & 4 & 3 & \\
\hline & 1 & 0 & 0 & 0 & \\
\hline & 0 & 0 & 0 & 0 & \\
\hline & Subtotal & 29 & 20 & 20 & \\
\hline & Soma & 103 & 103 & 102 & \\
\hline
\end{tabular}

Os resultados apresentados na Tabela 4 apresentam as subamostras da pesquisa. Esse agrupamento auxilia a compreender com mais clareza o objetivo do trabalho. A hipótese subjacente deste trabalho é de que empresas com "Alto" escore de governança apresentariam níveis de acrruals discricionários menores do que empresas classificadas com "baixo" escore de governança corporativa.

Na coluna "IGC", está a pontuação em rating nos anos de 2008, 2009 e 2010 e a quantidade de empresas para cada subgrupo.

$\mathrm{Na}$ sequência, está a média dos accruals discricionários (AD) das empresas classificadas com Alta, Média e Baixa governança. Ainda que a partir da tabela 4 não se possa fazer inferências sobre a relação entre os escores de Governança Corporativa e os accruals discricionários médios, é possível observar que a média de AD é menor em empresas com alto escore de Governança Corporativa.

O gráfico 1 complementa o exame da tabela anterior. Na medida em que se observa a presença de mecanismos de Governança Corporativa nas estruturas das empresas da amostra, menores são as médias dos accruals discricionários associadas.

Fonte: os autores

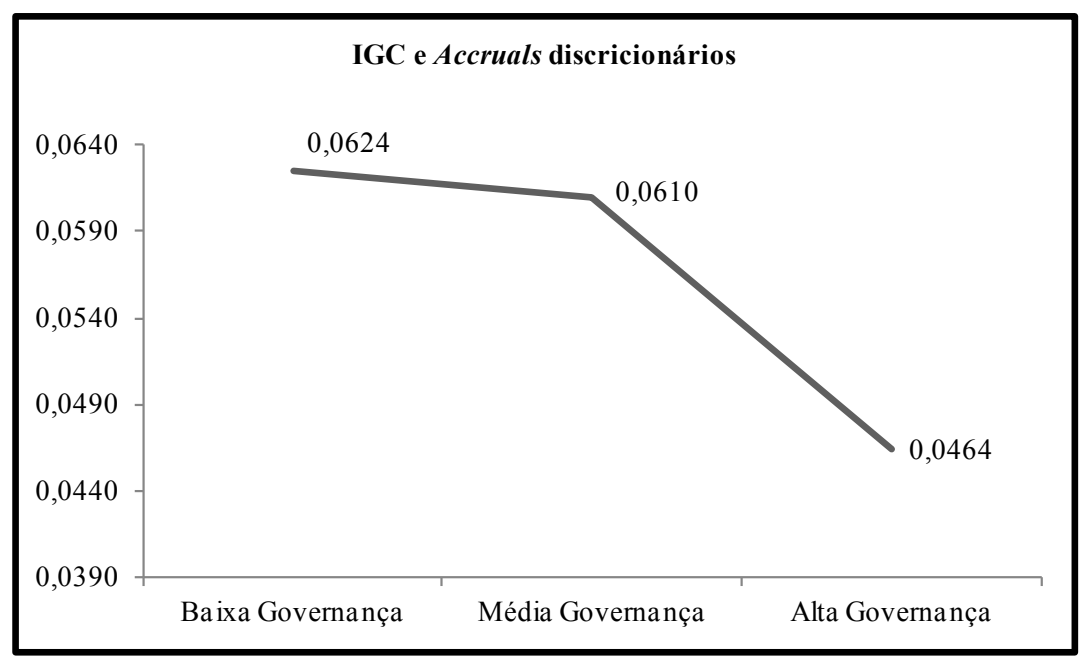

Gráfico 1. Desempenho dos accruals discricionários em relação ao

Índice amplo de Governança Corporativa.

Fonte: os autores.

Além disso, o gráfico 1 mostra que a diferença mais discrepante de média de accruals discricionários está entre o subgrupo de empresas de "alta" e "média" governança. Esse comportamento sugere o afastamento de empresas de "alta" governança no envolvimento de práticas de gerenciamento de resultados com menor incidência de accruals decorrentes da manipulação de resultados.

Embora o gráfico não descreva com exatidão a magnitude das diferenças de média da proxy de gerenciamento de resultados entre os três subgrupos do IGC, pode-se verificar que a curva tem desempenho monotônico indicando que à medida que evoluem os Índices de Governança Corporativa, os accruals discricionários também se movimentam e em direção contrária.

A tabela 5 exibe a matriz de correlações não paramétricas das variáveis de pesquisa e indica associação estatisticamente significativa do Índice de Governança Corporativa e todas as variáveis do estudo. 
Tabela 5: Matriz de Correlações (Spearman) das variáveis da pesquisa.

\begin{tabular}{|c|c|c|c|c|c|}
\hline & $I G C_{i t}$ & $A D_{i t}$ & $R O A i_{t-I}$ & $A L A V_{i t-I}$ & $T A M_{i t}$ \\
\hline \multirow{3}{*}{$I G C_{i t}$} & 1,000 &,$- 135^{*}$ &, $184^{* * *}$ &, $170^{* *}$ &, $335^{* * *}$ \\
\hline & . & ,018 & ,001 & ,003 & ,000 \\
\hline & 308 & 308 & 308 & 308 & 308 \\
\hline \multirow{3}{*}{$A D_{i t}$} &,$- 135^{*}$ & 1,000 &,- 019 & ,013 &,- 046 \\
\hline &, 018 & . &, 740 & ,816 & ,422 \\
\hline & 308 & 308 & 308 & 308 & 308 \\
\hline \multirow{3}{*}{$R O A i_{t-I}$} &, $184^{* *}$ &,- 019 & 1,000 &,$- 143^{*}$ &, $252^{* * *}$ \\
\hline &, 001 &, 740 & . &, 012 & ,000 \\
\hline & 308 & 308 & 308 & 308 & 308 \\
\hline \multirow{3}{*}{$A L A V_{i t-I}$} &, $170^{* *}$ & ,013 &,$- 143^{*}$ & 1,000 &, $382^{* *}$ \\
\hline &, 003 &, 816 &, 012 & . &, 000 \\
\hline & 308 & 308 & 308 & 308 & 308 \\
\hline \multirow{3}{*}{$T A M_{i t}$} &, $335^{* *}$ &,- 046 &, $252^{* * *}$ &, $382^{* * *}$ & 1,000 \\
\hline &, 000 & ,422 &, 000 &, 000 & . \\
\hline & 308 & 308 & 308 & 308 & 308 \\
\hline
\end{tabular}

$* * *, * *$ e $*$ significativos em $1 \%, 5 \%$ e $10 \%$.

Fonte: os autores.

Ao nível de 5\%, observa-se associação negativa entre os Índices de Governança Corporativa (IGC) e os accruals discricionários (AD) que, sem o rigor metodológico para afirmação de relação causa e efeito, tais resultados indicam que empresas com estruturas de governança mais ricas podem apresentar menores níveis de gerenciamento de resultados. Em seguida, ao nível de $1 \%$ de significância estatística, para as variáveis Tamanho $\left(T A M_{i t}\right)$, Retorno sobre os ativos $\left(R O A_{i t}\right)$ e Alavancagem $\left(A L A V_{i t}\right)$, a direção da associação ao IGC mostrou-se convergente ao de achados anteriores de pesquisas nacionais e internacionais.

\subsection{Análise não paramétrica das variáveis de pesquisa}

Em continuidade à análise da relação das variáveis do trabalho, na tabela 6, são apresentados os resultados do teste Mann U Whitney de diferenças de médias. Essa tabela tem como objetivo demonstrar diferenças significativas para a proxy de gerenciamento de resultados, tamanho, alavancagem e retorno sobre os ativos, em relação aos grupos de empresas que apresentam "Alta", "Média" e "Baixa" governança corporativa.

Tabela 6. Correlações entre as variáveis da pesquisa.

\begin{tabular}{|c|c|c|c|c|}
\hline & & 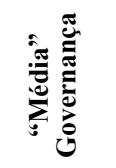 & 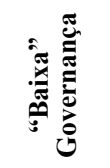 & Escore Z \\
\hline IGC & 0,7829 & 0,4386 & 0,2098 & - \\
\hline $\mathrm{AD}$ & 0,0464 & 0,0610 & 0,0624 & $-2,38 * * *$ \\
\hline TAM & 14,5324 & 14,3609 & 13,0627 & $-5,26^{* * *}$ \\
\hline ALAV & 0,1995 & 0,1491 & 0,1277 & $-2,50 * * *$ \\
\hline ROA & 0,0743 & 0,0779 & 0,0294 & $-2,56 * * *$ \\
\hline
\end{tabular}

$* * *, * *$ e $*$ significativos em $1 \%, 5 \%$ e $10 \%$.

Fonte: os autores.
Ao nível de significância de 1\%, a tabela 6 demonstra que a magnitude dos accruals discricionários de empresas com grau mais elevado de presença de atributos é menor diante daquelas que compõem o grupo com menor rating de Governança Corporativa. Assim, os resultados do teste não paramétrico de Mann U Whitney apresentam associação de direção negativa entre o índice utilizado como aproximação para governança e a proxy de gerenciamento de resultados. A partir das observações da tabela 6, para a amostra de dados da pesquisa, rejeita-se a hipótese de que maiores escores do Índice de Governança Corporativa (IGC) não estão associados a menores níveis de gerenciamento de resultados.

As diferenças apresentadas na tabela 6 sugerem que empresas com mais elevado grau de Governança Corporativa podem fazer escolhas contábeis que se materializem em menor nível de intervenções propositais sobre os resultados. Esse comportamento pode ter como causa a eficiência de práticas de monitoramento exercidas pela presença de mecanismos de governança. Desse modo, empresas bem governadas estariam menos inclinadas a exercer discricionariedade sobre os números contábeis contribuindo para a ampliação da qualidade da informação contábil divulgada ao público.

\section{CONSIDERAÇÕES FINAIS}

Argumenta-se que a contabilidade exerce papel importante para resolver problemas relativos a custos de agência, assimetria de informação e externalidades de partes não contratantes. As razões que enrobustecem essa importância são de que a contabilidade tem o papel central de demonstrar resultados de uso recorrente em relações contratuais; por constituir um meio pelo qual gestores disseminam informações de ordem qualitativa e quantitativa sobre o desempenho da empresa; e porque o nível de regulação do ordenamento contábil influencia a qualidade da informação contábil divulgada a usuário (FIELDS, LYS e VINCENT, 2001). Compreender a ligação da informação contábil e práticas de Governança Corporativa constituiu a motivação para a realização deste estudo.

Esta pesquisa teve como objetivo verificar a relação entre Governança Corporativa e gerenciamento de resultados contábeis. Para isso, foi utilizado como proxy de Governança Corporativa um índice amplo proposto por Leal e Carvalhal-da-Silva (2005) que contemplou as dimensões de Transparência, Composição e funcionamento do Conselho de Administração, Controle e Conduta, e Direitos de Acionistas. Como proxy de gerenciamento de Resultados, utilizaramse os accruals discricionários estimados a partir de variáveis instrumentais conforme modelo proposto Kang Sivaramakrishnan (1995).

Tendo-se rejeitado a hipótese nula de que maiores escores de Governança Corporativa não estão associados a menores níveis de Gerenciamento de Resultados contábeis, verificou-se que empresas agrupadas dentre aquelas com estruturas mais refinadas de Governança Corporativa apresentam menor intensidade de gerenciamento de resultados contábeis. A diferença observada na proporção de accruals discricionários que compõe o grupo daquelas com "Alta" governança pode ser explicada pela presença superior de mecanismos de 
incentivo e controle. Tal relação é consistente com a ideia da existência de um trade-off entre a adoção de atributos de governança e escolhas contábeis direcionadas a intervir propositalmente sobre os números contábeis com vistas a atender objetivos específicos da gestão.

Embora mediante utilização de percursos diferentes, as observações da amostra de pesquisa trazidas por este trabalho se coadunam ao de pesquisas internacionais com a mesma temática, em que se observa relação negativa de modelos superiores de governança e gerenciamento de resultados (BEKIRIS e DOUKAKIS, 2011; SHEN e CHIH, 2007; JIANG et al., 2008). Entretanto, pesquisas nacionais anteriores não evidenciaram que a adoção de boas práticas de Governança Corporativa está associada ao menor envolvimento de empresas de capital aberto com o gerenciamento de resultados (RAMOS e MARTINEZ, 2006; CARDOSO et al., 2006). Possíveis explicações para essa divergência de resultados podem estar na opção de utilização de diferentes proxies de Governança Corporativa e gerenciamento de resultados.

Tendo observado relação inversa entre Governança Corporativa e gerenciamento de resultados contábeis, esta pesquisa lança luz sobre aspectos interessantes da relação entre informação contábil e governança. Essa contribuição decorre de que este trabalho amplia o escopo de estudos que analisam a informação contábil a partir de índices amplos de governança, e reforça a possibilidade de que a presença de mecanismos de governança empresarial pode influenciar a qualidade da informação contábil divulgada ao usuário.

Os resultados apresentados nesta pesquisa devem ser interpretados com cautela, dado o fato de que o percurso metodológico para formação da amostra de pesquisa não utiliza recursos de uma amostra probabilística. Desse modo, essa limitação prejudica a generalização dos resultados encontrados. Para exame da persistência dos achados deste trabalho em pesquisas futuras, sugere-se a utilização de série temporal mais longa e com o número máximo de empresas, o que poderá ensejar em um painel de dados desbalanceado possibilitando análises de diferenças individuais das empresas e entre setores econômicos. Neste percurso sugerido, recomendase a adição de variáveis de controle em modelos de análise multivariada para exame da regularidade dessas variáveis, o que irá auxiliar na generalização da relação entre Governança Corporativa e gerenciamento de resultados contábeis.

\section{REFERÊNCIAS}

ADKINS, Lee C., Using Gretl for Principles of Econometrics. Disponível em: http://www. learneconometrics.com/gretl/ebook.pdf. Acesso em: 01.09.2011.

BAPTISTA, Evelyn Maria Bóia. Análise do perfil das empresas brasileiras segundo nível o nível de gerenciamento de resultados - Uma abordagem multivariada. In: III CONGRESSO DA ASSOCIAÇÃO NACIONAL DOS PROGRAMAS DE PÓS-GRADUAÇÃO EM CIÊNCIAS CONTÁBEIS, 2009, São Paulo. Anais do ANCONT 2009, 2009. 1 CD-ROM.

BEKIRIS, F. V., DOUKAKIS, L. Corporate Governance and Accruals Earnings Management. Managerial and Decision Economics, v.32, p-439-456, 2011.

BLACK, B.S; JANG, H.; KIM, W. Does corporate governance affects firms' market values? Evidence from Korea. Stanford Law and Economics. Olin Working paper n.237; Disponivel em: $<$ http://ssrn. com/abstract=311275 > Acesso em: 01/07/2012.

BOWEN, R., RAJGOPAL, S., VENKATACHALAM, M. Accounting Discretion, Corporate Governance and Firm Performance. Contemporary Accounting Research, v. 25, n. 02, p-351-405, 2008.

BROWN, Laurance D.; CAYLOS, Marcus. Corporate governance and firm operating performance. Review of Quantitative Finance and Accounting. v. 32, n.2, p.129-144,2009.

BUTT, U; Profits, Financial Leverage and Corporate Governance. McMaster University - Michael G. DeGroote School of Business. Disponivel em: $<$ http://ssrn.com/abstract $=1929168>\quad$ Acesso em $06 / 05 / 2012$.

BUSHMAN, Robert M.; SMITH, Abbie J. Financial Accounting Information and Corporate Governance. Journal of Accounting and Economics, v. 32 p. 237-333, 2001.

CARDOSO, Ricardo Lopes; AQUINO, André Carlos Busanelli; ALMEIDA, José Elias Feres; NEVES, Antônio José Barbosa. Acumulações Discricionárias, Liquidez e Governança Corporativa Divulgada no Brasil. In: XXX ENCONTRO ANUAL DA ASSOCIAÇÃO NACIONAL DOS PROGRAMAS DE PÓS-GRADUAÇÃO EM ADMINISTRAÇÃO, 2006, Salvador. Anais do ENANPAD 2006, 2006. 1 CD-ROM.

CARDOSO, Ricardo Lopes. Governança Corporativa ou Gerenciamento de Resultados? Revista Brasileira de Contabilidade, n.150, p. 18-37, Novembro, 2004.

CARVALHAL-DA-SILVA, André Luiz; LEAL, Ricardo Pereira. Corporate governance index, firm valuation and performance in Brazil. Revista Brasileira de Finanças, v. 3, No 1, p.1-18, 2005.

LEAL, Ricardo Pereira; CARVALHAL-DA-SILVA, André Luiz. Corporate governance index, firm valuation and performance in Brazil. Revista Brasileira de Finanças, v. 3, No 1, p.1-18, 2005.

CHEN, Ken Y.; ELDER, Randal J.; HSIEH, Yung-Ming. Corporate Governance and Earnings Management: The Implications of Corporate Governance Best-practices Principles for Taiwanese Listed Companies. Accepted Paper Series, April, 2007. Disponível em $<$ http://ssrn.com/abstract=981926>. Acesso em Janeiro de 2012.

CLAESSENS, S.; FAN, J.P.H. Corporate governance in Asia: a survey. International Review of Finance, Oxford, v.3, n.2, p.71-103, Aug. 2002.

COELHO, Antônio Carlos. LOPES, Alexsandro Broedel. Avaliação Da Prática de apropriação discricionária na Apuração de Lucro Por Companhias Abertas Brasileiras Conforme Seu Grau de Alavancagem. In: XXIX ENCONTRO ANUAL DA ASSOCIAÇÃO NACIONALDOS PROGRAMAS DE PÓSGRADUAÇÃO EM ADMINISTRAÇÃO, 2005, 
Brasília. Anais do ENANPAD 2005, 2005. 1 CDROM.

COHEN, Jeffrey; KRISHNAMURTHY, Ganesh. WRIGHT, Arnie M. Corporate Mosaic and Financial Reporting. Journal of Accounting Literature, v. 23, p.87-152, 2004.

DECHOW, Patricia.M., SLOAN, R.G., SWEENY, A.P. Detecting Earnings Management. The Accounting Review. v. 70, No. 2, p.193-225, 1995.

FAMA, Eugene F. Agency Problems and the Theory of the Firm. The Journal of Political Economy, v. 88, No. 2, p. 288-307, 1980.

FAMA, Eugene F.; JENSEN, Michael C. Separation of Ownership and Control. Journal of Law and Economics. v. XXVI, June 1983. Disponível em http://papers.ssrn.com/abstract=94034. Acesso: 13.01.2011.

FIELD, Andy. Descobrindo estatística usando SPSS. Tradução: Lorí Viali. - 2. ed.- Porto Alegre: Artmed, 2009

FIELDS, Thomas D.; LYS, Thomas Z.; VINCENT, Linda. Empirical research on accounting

choice. Journal of Accounting and Economics, v. 31, p. 255-307, 2001.

GILLAN, Stuart L. STARKS, Laura T. A survey of shareholder activism: Motivation and empirical evidence, Contemporary Finance Digest, v.3, p. 10-34, 1998.

GREENE, William H. Econometrics Analysis. New Jersey: Prentice Hall, 2003.

GUJARATI, Damodar N. Basic Econometrics. 4th. Ed. Mcgraw-Hill, 2004.

HEALY P. M.; WAHLEN, J. M. A review of the earnings management literature and its implications for standard setting. Accounting Horizons, v. 13, pp. 365-383. 1999.

JENSEN, Michael C. Organization Theory and Methodology. The Accounting Review. v.56, p. 319-338, 1983.

JENSEN, Michael C.; MECKLING, William H. Theory of the Firm: Managerial Behavior, Agency Costs and Ownership Structure. Journal Of Financial Economics, v.3, No. 4, p. 305-350, 1976.

JIANG, W. LEE, P. ANANDARAJAN, A. The association between corporate governance and earnings quality: further evidence using the GOVscore. Advances in Accounting, incorporating Advances in International Accounting v. 24: 193228, 2008.

JONES, J. J. Earnings management during import relief investigations. Journal of Accounting Research. v. 29, n. 2, p. 193-228, 1991.

KANG, S.H.; SIVARAMAKRISHANAN, K.; Issues in testing earnings management: an instrumental variable approach. Journal of Accounting Research, v. 33 No.2, p.353-367, 1995.

KLAPPER, L; LOVE, I; Corporate Governance, investor protection and performance in emerging markets. Journal of Corporate Finance, Amsterdã, v. 10, n.5, p.703-728, Nov.2004.

LA PORTA, Rafael; LOPEZ-DE-SILANES, Florêncio; SHLEIFER, Andrei. VISHNY, Robert. Investor protection and corporate governance. Journal of Financial Economics, v. 58, p. 3-27, October, 2000.

LA PORTA, Rafael; LOPEZ-DE-SILANES, Florêncio; SHLEIFER, Andrei. VISHNY, Robert. Investor protection and corporate valuation. Journal of Finance, p.3-53.

LA PORTA, Rafael; LOPEZ-DE-SILANES, Florêncio; SHLEIFER, Andrei;. Corporate ownership around the world. Journal of Finance, v. 54, p. 471-517, 1999.

LARCKER, David; RICHARDSON, Scott; TUNA, Irem. Corporate Governance, Accounting Outcomes and Organizational Performance. The Accounting Review, v.82, n.84, p. 963-1008, 2007.

LEAL, Ricardo Pereira câmara. Governance practices and corporate value: a recent literature survey. Revista de Administração, v.39, p. 327-337, 2004.

LEAL, Ricardo Pereira Câmara; CARVALHALDA-SILVA, André; VALADARES, Sílvia Mourthé. Estrutura de controle e propriedade das companhias brasileiras de capital aberto. Revista de Administração Contemporânea, v.6, No. 1, p. $7-18,2002$.

LOPES, Alexandro Broedel. A Teoria dos Contratos, Governança Corporativa e contabilidade, In: Teoria Avançada da Contabilidade. São Paulo: Ed. Atlas, 2004.

LOPES, Alexandro Broedel. WALKER, Martin. Firmlevel incentives and informativeness of accounting reports: an experiment in Brazil. Feb. 2008

MARTINEZ, A. L.; RAMOS, Gizele Martins Governança Corporativa e Earnings Management. Revista Contemporânea de Contabilidade, Florianopolis, v.1, No. 6, p. 143-164, 2006.

MARTINEZ, Antônio Lopo. "Gerenciamento" dos resultados contábeis: estudo empírico das companhias abertas brasileiras. São Paulo. Tese (Doutorado em Contabilidade e Controladoria) - Faculdade de Economia Administração e Contabilidade da Universidade de São Paulo. São Paulo, 2001.

MCNICHOLS, F. Research design issues in earnings management studies. Journal of Accounting and Public Policy, n. 19, p. 313-345, 2000.

NARDI, Paula Carolina Ciampaglia. NAKAO, Sílvio Hiroshi. Gerenciamento de Resultados e a Relação com o custo da dívida das empresas brasileiras de capital aberto. Revista de Contabilidade e Finanças da USP, v.20, No.50, p.77-100, 2009.

SCHIPPER, Katherine. Commentary on Earnings Management. Accounting Horizons, v. 3, p.91102, 1989.

SHAH, Syed Zulfiqar; BUTT, Safdar A; HASSAN, Aarshad. Corporate Governance and Earnings Management: an Empirical Evidence From Pakistani Listed Companies. European Journal of Scientific Research, v. 26, p.624-638, 2009. 
SHEN, C.; CHIH, H. Earnings management and corporate governance in Asia's emerging markets. Corporate Governance: An international Review, v.15 p. 999-1021. 2007

SHLEIFER, Andrei, VISHNY, Robert. A survey of corporate governance. Journal of Finance, v. 52, n. 2, p. 737-783, June, 1997.

SILVEIRA, Alexandre Di Miceli. Governança corporativa e estrutura de propriedade: determinantes e relação com o desempenho das empresas no Brasil. Tese (Doutorado em Administração) - Faculdade de Economia, Administração e Contabilidade da Universidade São Paulo. São Paulo, 2004.

SLOAN, Richard G. Financial accounting and corporate governance: a discussion. Journal of Accounting and Economics. USA, n. 32. p. 335-347, 2001.

STOCK, James; YOGO, Motohiro. Testing for weak instruments in linear IV regression, in Andrews, Donald W. K. and James H. Stock, eds, 'Identication and Inference for Econometric Models: Essays in Honor of Thomas Rothenberg', Cambridge University Press, p. 80-108.

TORRES, Damiana; BRUNI, Adriano Leal; RIVERACASTRO, Miguel Angel; MARTINEZ, Antônio Lopo. Estrutura de Propriedade e Controle, Governança Corporativa e o Alisamento de Resultados no Brasil. In: XXXIII ENCONTRO ANUAL DA ASSOCIAÇÃO NACIONALDOS PROGRAMAS DE PÓS-GRADUAÇÃO EM ADMINISTRAÇÃO, 2009, São Paulo. Anais do ENANPAD 2009, 2009. 1 CD-ROM.

VALADARES, S.M.; LEAL, R.P.C. Ownership and control structure of Brazilian companies. Abante, Santiago, v.3, n.1, p.29-56, Abr. 2000.

WATTS, Ross L.; ZIMMERMAN Jerold L. Positive Accounting Theory. New Jersey: Prentice-hall, 1986.

ZINGALES, Luigi. Corporate Governance. The New Palgrave Dictionary of Economics and the Law, Working Paper Series, June, 1998. Disponível $<$ http://ssrn.com/abstract=46906>. Acesso em Dezembro de 2011. 